\title{
Body Mass Index and the Prevalence of Hypertension and Dyslipidemia
}

\author{
Clarice D. Brown, * Millicent Higgins, $\dagger$ Karen A. Donato $\neq$ Frederick C. Rohde $\$$ Robert Garrison, $\S$ \\ Eva Obarzanek, $\neq$ Nancy D. Ernst $\neq$ and Michael Horan $\neq$
}

\begin{abstract}
BROWN, CLARICE D., MILLICENT HIGGINS, KAREN A. DONATO, FREDERICK C. ROHDE, ROBERT GARRISON, EVA OBARZANEK, NANCY D. ERNST, AND MICHAEL HORAN. Body mass index and the prevalence of hypertension and dyslipidemia. Obes Res. 2000;8:605-619.

Objective: To describe and evaluate relationships between body mass index (BMI) and blood pressure, cholesterol, high-density lipoprotein-cholesterol (HDL-C), and hypertension and dyslipidemia.
\end{abstract}

Research Methods and Procedures: A national survey of adults in the United States that included measurement of height, weight, blood pressure, and lipids (National Health and Nutrition Examination Survey III 1988-1994). Crude age-adjusted, age-specific means and proportions, and multivariate odds ratios that quantify the association between hypertension or dyslipidemia and BMI, controlling for race/ethnicity, education, and smoking habits are presented.

Results: More than one-half of the adult population is overweight (BMI of 25 to 29.9) or obese (BMI of $\geq 30$ ). The prevalence of high blood pressure and mean levels of systolic and diastolic blood pressure increased as BMI increased at ages younger than 60 years. The prevalence of high blood cholesterol and mean levels of cholesterol were higher at BMI levels over 25 rather than below 25 but did not increase consistently with increasing BMI above 25 . Rates of low HDL-C increased and mean levels of HDL-C decreased as levels of BMI increased. The associations of

\footnotetext{
Submitted for publication April 4, 2000

Accepted for publication in final form September 5, 2000.

*CODA Research, Silver Spring, Maryland; $\nmid$ Departments of Epidemiology and Internal Medicine, University of Michigan, Ann Arbor, Michigan; $\$$ National Heart, Lung, and Blood Institute, National Institutes of Health, Bethesda, Maryland; and §Jackson Heart Study Coordinating Center, Jackson State University, Jackson, Mississippi.

Address correspondence to Karen Donato, Coordinator, NHLBI Obesity Education Initiative, National Heart, Lung, and Blood Institute, 31 Center Drive MSC. 2480, Bethesda, MD 20892-2480. E-mail: donatok@nhlbi.nih.gov

Copyright (C) 2000 NAASO
}

BMI with high blood pressure and abnormal lipids were statistically significant after controlling for age, race or ethnicity, education, and smoking; odds ratios were highest at ages 20 to 39 but most trends were apparent at older ages. Within BMI categories, hypertension was more prevalent and HDL-C levels were higher in black than white or Mexican American men and women.

Discussion: These data quantify the strong associations of BMI with hypertension and abnormal lipids. They are consistent with the national emphasis on prevention and control of overweight and obesity and indicate that blood pressure and cholesterol measurement and control are especially important for overweight and obese people.

Key words: blood pressure, blood cholesterol, high density lipoprotein-cholesterol, overweight, obesity

\section{Introduction}

Obesity is an independent risk factor for cardiovascular disease, type 2 diabetes, gallbladder disease, cancers at several sites, osteoarthritis, and total mortality (1-20). A recent report described associations between overweight and obesity and the prevalence of chronic conditions including high blood pressure and high blood cholesterol levels in National Health and Nutrition Examination Survey (NHANES) III data (19). Associations between obesity and high blood pressure, high blood cholesterol, and low levels of high density lipoprotein-cholesterol (HDL-C) have been shown in men and women and in diverse race/ethnic groups (6-19).

The prevalence of overweight and obesity is increasing, and obesity is now estimated to be the second leading cause of preventable death after cigarette smoking in the United States (21-24). By contrast, national trends in blood pressure and hypertension and in blood cholesterol and hypercholesterolemia over the past two decades have been favorable (23,25-28). Levels of HDL-C increased slightly although not consistently in older adults $(27,28)$. These 
favorable trends have probably not achieved their full potential because of the increasing prevalence of overweight. The increased prevalence of over-weight among children and adolescents (29) may affect adversely future trends of hypertension and high blood cholesterol.

Although the terms overweight and obesity are often used interchangeably, overweight refers to an excess of body weight compared with height; obesity refers to an excess of body fat. In populations in which high levels of adiposity are common, such as the population of the United States, excess body fat or adiposity is highly correlated with body weight (30). Thus, under these conditions, body mass index (BMI) is a convenient and valid measure of adiposity. BMI is calculated by dividing the weight in kilograms by the square of height in meters $\left(\mathrm{kg} / \mathrm{m}^{2}\right)$. A recent review supports the use of BMI in clinical practice $(31,32)$ to define overweight (BMI of 25 to 29.9) and obesity (BMI of $\geq 30$ ).

The present report provides detailed information on the distribution of blood pressure and total cholesterol, and on the prevalence of hypertension and dyslipidemia, in relation to levels of BMI for representative samples of white, black, and Mexican American adults in the United States. It presents new information on relationships between BMI and HDL-C. The results, based on the Sixth Report of the Joint National Committee on Prevention, Detection, Evaluation, and Treatment of High Blood Pressure (JNC VI) and National Cholesterol Education Program (NCEP) definitions of high blood pressure and high blood cholesterol, are relevant to clinical practice and public health approaches to reducing the burden of overweight, obesity, cardiovascular disease, and related conditions.

\section{Research Methods and Procedures}

\section{Data Source}

The NHANES are multipurpose health examination surveys that estimate the prevalence of chronic diseases and associated risk factors for representative samples of the civilian, noninstitutionalized population of the United States. The third NHANES survey (NHANES III) was conducted in two 3-year phases between 1988 and 1994. Data for all 6 years of NHANES III are presented here. The survey consisted of an interview and examination in the home and a detailed examination in a mobile examination center. Detailed descriptions of the design and conduct of NHANES have been reported $(33,34)$. The cardiovascular component was designed in cooperation with the National Heart, Lung, and Blood Institute. The protocols for measurement of blood pressure, height and weight, and venipuncture and laboratory methods for lipid determinations have been published previously $(21,25,27)$. An interviewer measured blood pressure three times with the participant resting quietly, sitting in a chair at home. A physician took three additional blood pressure measurements in the mobile examination center. In both venues, blood pressure was measured with a standard sphygmomanometer (W. A. Baum, Copiague, NY). One of four cuff sizes (pediatric, regular adult, large, or thigh) was chosen based on the circumference of the participant's arm, as indicated by the manufacturer's guidelines. Total cholesterol and HDL-C levels were measured in blood specimens obtained during the examination in a mobile examination center. All lipid measurements were based on a single blood determination. Adults were weighed without shoes in a hospital gown with an electronic-load cell scale in kilograms to two decimal places. Height was measured without shoes with a fixed stadiometer and recorded to the nearest millimeter.

Complete data on age and race/ethnicity were available for 8816 men and 10,009 women aged 20 years and older, excluding pregnant women. Approximately $98 \%$ of men and women had three to six blood pressure measurements and information on current use of antihypertensive medication, $85 \%$ of both sexes had total cholesterol and HDL-C data, and $90 \%$ of men and $87 \%$ of women had data on BMI. Because of combinations of missing data, sample sizes varied, from 16,681 in Table 1 (only persons with missing BMI were excluded) to 15,645 for the high blood cholesterol model in Table 6 (persons with missing data on BMI, cholesterol, current smoking status, or education were excluded).

\section{Definitions}

Four categories of BMI $(<25 ; 25$ to $<27 ; 27$ to $<30$; and $\geq 30 \mathrm{~kg} / \mathrm{m}^{2}$ ) were compared. These categories were selected to correspond to various national and international recommendations to define healthy weight (BMI of 18.5 to 24.9), overweight (BMI of 25 to 29.9), and obesity (BMI of $\geq 30$ ) (32,35-39). High blood pressure was defined as mean systolic blood pressure $\geq 140 \mathrm{~mm} \mathrm{Hg}$, mean diastolic blood pressure $\geq 90 \mathrm{~mm} \mathrm{Hg}$, or current use of antihypertensive medication (25). This definition is consistent with the clinical definition of high blood pressure in the JNC VI (40). The means of three or more blood pressure readings obtained either at home or in the mobile examination center were used in these analyses.

High blood cholesterol was defined as total serum cholesterol $\geq 240 \mathrm{mg} / \mathrm{dL}(6.21 \mathrm{mM})$. Low HDL-C was defined as $<35 \mathrm{mg} / \mathrm{dL}(0.91 \mathrm{mM})$ in men and $<45 \mathrm{mg} / \mathrm{dL}(1.16$ $\mathrm{mM}$ ) in women (27) to reflect the higher mean in women than men. This definition is different from that used by NCEP's second Adult Treatment Panel (41).

Dyslipidemia was defined in some analyses as a ratio of total cholesterol to HDL-C of $\geq 4.5$. The same definition was used for men and women. 
Table 1. Distribution of population by BMI*

\begin{tabular}{|c|c|c|c|c|c|c|c|c|c|c|}
\hline & \multirow[b]{2}{*}{$N$} & \multirow[b]{2}{*}{ Population } & \multicolumn{2}{|c|}{ BMI $<25$} & \multicolumn{2}{|c|}{$25 \leq$ BMI $<27$} & \multicolumn{2}{|c|}{$27 \leq \mathrm{BMI}<30$} & \multicolumn{2}{|c|}{$30 \leq \mathrm{BMI}$} \\
\hline & & & $\%$ & (SE) & $\%$ & (SE) & $\%$ & (SE) & $\%$ & (SE) \\
\hline Male & 7,933 & $84,298,756$ & 40.6 & $(1.00)$ & 19.6 & $(0.62)$ & 20.3 & $(0.73)$ & 19.5 & $(0.69)$ \\
\hline Non-Hispanic white & 3,285 & $64,578,856$ & 39.4 & $(1.22)$ & 20.1 & $(0.70)$ & 20.6 & $(0.89)$ & 19.9 & $(0.84)$ \\
\hline Non-Hispanic black & 2,112 & $8,538,154$ & 43.3 & $(1.18)$ & 16.9 & $(0.90)$ & 19.0 & $(0.89)$ & 20.7 & $(0.96)$ \\
\hline Mexican American & 2,250 & $4,681,642$ & 36.1 & $(1.45)$ & 19.8 & $(1.38)$ & 23.5 & $(0.97)$ & 20.6 & (1.21) \\
\hline 20 to 39 & 3,109 & $40,324,739$ & 49.1 & $(1.30)$ & 19.1 & (1.07) & 16.8 & $(1.07)$ & 15.0 & $(0.84)$ \\
\hline 40 to 59 & 2,080 & $26,847,824$ & 31.6 & $(1.75)$ & 20.0 & $(1.25)$ & 23.0 & $(1.20)$ & 25.4 & (1.16) \\
\hline 60 to 79 & 2,049 & $15,016,085$ & 32.5 & $(1.53)$ & 19.5 & (1.06) & 25.1 & $(1.42)$ & 22.9 & $(1.50)$ \\
\hline $80+$ & 695 & $2,110,108$ & 49.4 & $(2.35)$ & 22.8 & $(1.95)$ & 19.9 & $(1.28)$ & 8.0 & (1.17) \\
\hline Female & 8,748 & $89,762,709$ & 49.3 & $(1.02)$ & 12.6 & $(0.51)$ & 13.1 & $(0.44)$ & 25.0 & $(0.93)$ \\
\hline Non-Hispanic white & 3,755 & $68,428,594$ & 52.6 & $(1.25)$ & 12.2 & $(0.63)$ & 12.6 & $(0.54)$ & 22.7 & (1.12) \\
\hline Non-Hispanic black & 2,490 & $10,394,909$ & 34.0 & $(1.42)$ & 12.1 & $(0.79)$ & 17.3 & $(0.61)$ & 36.7 & (1.39) \\
\hline Mexican American & 2,128 & $3,986,314$ & 34.1 & $(1.43)$ & 14.3 & $(0.87)$ & 18.2 & $(0.94)$ & 33.3 & (1.34) \\
\hline 20 to 39 & 3,445 & $38,743,665$ & 59.4 & $(1.44)$ & 10.8 & $(0.81)$ & 9.1 & $(0.74)$ & 20.6 & (1.26) \\
\hline 40 to 59 & 2,363 & $28,168,773$ & 42.6 & $(1.78)$ & 12.3 & $(0.91)$ & 14.7 & $(1.19)$ & 30.4 & $(1.53)$ \\
\hline 60 to 79 & 2,159 & $18,888,587$ & 38.6 & $(1.47)$ & 15.9 & $(1.02)$ & 17.7 & $(0.92)$ & 27.8 & (1.16) \\
\hline $80+$ & 781 & $3,961,685$ & 49.9 & $(1.57)$ & 16.3 & $(1.28)$ & 18.7 & $(1.55)$ & 15.1 & (1.41) \\
\hline
\end{tabular}

* Age 20 and older, excluding pregnant women.

Current smokers had smoked 100 cigarettes or more in their lifetime and smoked currently; nonsmokers were not smoking currently.

\section{Statistical Methodology}

Analyses used the 6-year (1988 to 1994) data from NHANES III and SUDAAN software (Research Triangle Institute, Research Triangle Park, NC), which takes into account the stratified cluster sample design and oversampling of certain population subgroups $(33,42,43)$. National estimates were determined by using sample weights in all analyses. Crude and/or age-adjusted prevalence estimates, means, and SEs are provided by BMI category for nonHispanic white, non-Hispanic black, and Mexican American men and nonpregnant women of $\geq 20$ years of age. Age was adjusted to the estimated year 2000 standard population by the direct method using 10-year age groups. Age-specific estimates are given for ages 20 to 39, 40 to 59, 60 to 79, and $\geq 80$. The sample sizes for 80 and over were small; they were included in the 60 and over age groups in some analyses. SEs were calculated by a technique for complex survey design and estimation procedures (42). Odds ratios were calculated using logistic regression analyses performed separately for men and women. The models were identical for each risk factor and included direct effects for the categorical variables BMI, race/ethnicity, smoking, and age, and interactions between BMI and race/ethnicity and BMI and age; education was entered as a continuous variable (years of education). To estimate odds ratios incorporating the interaction effects for both sexes from Table 6 , the BMI odds ratio was multiplied by the odds ratios for age or race/ethnicity and by the interaction terms. Reference categories were BMI $<25$, non-Hispanic white, nonsmoker, and aged 20 to 39 years as appropriate. Age group and race/ ethnicity were also used as stratifying variables in the figures; odds ratios were estimated separately for each group.

\section{Results}

\section{Distribution of BMI}

As reported previously (21), the distribution of BMI varied with sex, race/ethnicity, and age (Table 1). Greater proportions of women than men had BMIs at the extremes of the distribution (BMI of $<25$ and BMI of $\geq 30$ ). Among men, a smaller proportion of Mexican American men had a BMI of $<25$. The proportions of men in the highest BMI category were similar among the three race/ethnic groups. Compared with white women, black and Mexican American women had smaller proportions at the lowest level of BMI and higher proportions at BMI levels of $>27$.

The proportion of men and women at the lowest level of BMI $(<25)$ decreased with increasing age from 20 to 39 years through ages 60 to 79 years. The proportions at the 
highest BMI level ( $\geq 30$ ) were largest at ages 40 to 59 years. Nearly half of the small numbers of men and women aged 80 and older had a BMI $<25$, whereas only $8 \%$ of these men and $15 \%$ of these women were obese.

\section{Blood Pressure}

Mean systolic and diastolic blood pressures increased with increasing BMI in men and women (Table 2). Systolic blood pressure was $\sim 9 \mathrm{~mm} \mathrm{Hg}$ higher for men (131 vs. 121 $\mathrm{mm} \mathrm{Hg}$ ) and $\sim 11 \mathrm{~mm} \mathrm{Hg}$ higher for women (116 vs. 127 $\mathrm{mm} \mathrm{Hg}$ ) in the highest BMI category $(\geq 30)$ compared with the lowest BMI category $(<25)$. The difference in diastolic blood pressure between the highest BMI category and the lowest BMI category was $\sim 7 \mathrm{~mm} \mathrm{Hg}$ for men and $\sim 6 \mathrm{~mm}$ $\mathrm{Hg}$ for women. The expected higher mean blood pressures at older ages were seen within each BMI category for systolic pressure, but diastolic pressures were lower at ages over 60 years in both sexes.

Among men, the prevalence of high blood pressure increased progressively with increasing BMI, from $15 \%$ at a BMI of $<25$ to $42 \%$ at a BMI of $\geq 30$ (Table 3). The trend of higher prevalence of high blood pressure with increasing BMI was similar for white, black, and Mexican American men, but the age-adjusted rates were highest among black men within each level of BMI (see Figure 2). The prevalence of high blood pressure increased with age among men at all levels of BMI. The increase in high blood pressure with increasing BMI was greater in the two younger age groups (Table 3 and Figure 1). Among men aged 20 to 39 years, the prevalence of high blood pressure was seven times higher at the highest $(\geq 30)$ BMI compared with the lowest $(<25)$ BMI category. Among older men $(60$ to 79 and over 80) there was a less steep increase in high blood pressure prevalence with increasing BMI category.

Women showed a pattern similar to that of men with respect to prevalence and relationship of high blood pressure to BMI (Table 3 and Figure 1). The prevalence of high blood pressure increased progressively from $15 \%$ among women with a BMI of $<25$ to $38 \%$ among women with a BMI of $\geq 30$. The increased prevalence of high blood pressure with increasing BMI was present in white, black, and Mexican American women; however, the age-adjusted prevalence of high blood pressure was highest among black women at every level of BMI (Figure 2). The prevalence of high blood pressure increased with age among women at all levels of BMI. The relationship of high blood pressure with increasing BMI was present in all age groups but it was steeper in the younger age groups (Table 3 and Figure 1). At $<60$ years of age, women with a BMI of $\geq 27$ had two to four or more times the prevalence of high blood pressure compared with women with a BMI of $<25$. Among older women, the prevalence of high blood pressure was generally higher in overweight and obese women than in leaner women. Odds ratios for high blood pressure adjusted for race/ethnicity, education, and current smoking habits are shown for age-specific groups in Figure 3, where the greater odds ratios for high blood pressure at younger ages are apparent. When BMI, age group, smoking habits and education were in the model, black men and black women had significantly higher prevalences of high blood pressure than white men and women, whereas prevalence rates were significantly lower in Mexican American than white men and women (data not shown). Education was related inversely to the prevalence of high blood pressure in men and women. Women, but not men, who smoked had lower rates of hypertension (Table 6). Interactions of the relationships of BMI with risk factors among age and race/ethnic groups are described below.

\section{Blood Cholesterol}

Mean serum cholesterol levels increased with increasing BMI from $193 \mathrm{mg} / \mathrm{dL}$ among men at the lowest BMI category to $211 \mathrm{mg} / \mathrm{dL}$ in men at the highest category of BMI (Table 4). Among women, total cholesterol levels increased from $195 \mathrm{mg} / \mathrm{dL}$ at the lowest BMI category to $217 \mathrm{mg} / \mathrm{dL}$ at the highest BMI level. In both sexes, cholesterol means were consistently lowest at BMIs of $<25$ but did not vary much with increasing BMI above 25 .

Among men, the prevalence of high blood cholesterol ranged from $13 \%$ at the lowest BMI level to $22 \%$ at the highest BMI level. The age-adjusted prevalence of high blood cholesterol increased with increasing BMI in white, black, and Mexican American men, but prevalence rates were lower in black and Mexican American men except among obese men. (Table 5 and Figure 2). The rise in prevalence of high blood cholesterol associated with increasing BMI was greatest among younger men. Men aged 20 to 39 years with a BMI of $\geq 27$ had more than twice the prevalence of high blood cholesterol as men of that age with a BMI of $<25$. A similar but less steep trend was apparent at older ages. At all levels of BMI, the prevalence of high blood cholesterol among men increased from ages 20 to 39 to ages 40 to 59, remained fairly stable in the group aged 60 to 79 , and then declined in the oldest age group (Table 5 and Figure 1).

The prevalence of high blood cholesterol increased from $13 \%$ among women at the lowest BMI level $(<25)$ to $27 \%$ to $30 \%$ among women with higher BMI levels; however, there was no consistent rise with increasing BMI above 25 (Table 5). Trends were similar for white, black, and Mexican American women. Hypercholesterolemia was generally more prevalent in white than in other women (Figure 2). The prevalence of high blood cholesterol among women increased with age, through ages 60 to 79 , then decreased at all levels of BMI. The increase in prevalence with increasing BMI was greatest in the younger age groups, and most 
Table 2. Mean systolic and diastolic blood pressure by BMI*

\begin{tabular}{|c|c|c|c|c|c|c|c|c|c|c|}
\hline & \multicolumn{2}{|c|}{ BMI $<25$} & \multicolumn{2}{|c|}{$25 \leq \mathrm{BMI}<27$} & \multicolumn{2}{|c|}{$27 \leq \mathrm{BMI}<30$} & \multicolumn{2}{|c|}{$30 \leq \mathrm{BMI}$} & \multicolumn{2}{|c|}{ Total $\dagger$} \\
\hline & Mean & (SE) & Mean & (SE) & Mean & (SE) & Mean & (SE) & Mean & (SE) \\
\hline \multicolumn{11}{|c|}{ Mean systolic blood pressure (mm Hg) } \\
\hline Male & 121.3 & $(0.47)$ & 124.5 & $(0.73)$ & 126.4 & $(0.62)$ & 130.7 & $(0.62)$ & 124.8 & $(0.40)$ \\
\hline 20 to 39 & 116.3 & $(0.47)$ & 118.8 & $(0.57)$ & 120.2 & $(0.58)$ & 125.2 & $(0.69)$ & 118.7 & $(0.33)$ \\
\hline 40 to 59 & 122.2 & $(0.70)$ & 123.9 & $(1.26)$ & 125.9 & (1.18) & 130.7 & $(1.03)$ & 125.6 & $(0.50)$ \\
\hline 60 to 79 & 135.7 & $(0.99)$ & 137.5 & $(1.26)$ & 136.4 & $(1.12)$ & 139.4 & (1.17) & 137.1 & $(0.61)$ \\
\hline $80+$ & 143.5 & $(1.51)$ & 144.4 & $(1.42)$ & 145.1 & $(2.02)$ & 141.6 & $(2.36)$ & 143.8 & $(0.93)$ \\
\hline Female & 115.7 & $(0.58)$ & 122.0 & $(0.76)$ & 125.7 & $(0.96)$ & 127.3 & $(0.54)$ & 120.3 & $(0.51)$ \\
\hline 20 to 39 & 106.9 & $(0.34)$ & 109.3 & $(0.58)$ & 111.4 & $(0.74)$ & 115.3 & $(0.53)$ & 109.1 & $(0.30)$ \\
\hline 40 to 59 & 115.6 & $(0.66)$ & 119.3 & $(1.26)$ & 122.9 & $(1.12)$ & 128.6 & $(0.75)$ & 121.0 & $(0.49)$ \\
\hline 60 to 79 & 135.8 & $(1.02)$ & 137.1 & $(1.49)$ & 138.7 & $(1.14)$ & 141.4 & $(0.71)$ & 138.1 & $(0.62)$ \\
\hline $80+$ & 148.3 & $(1.22)$ & 150.5 & (1.94) & 151.9 & $(1.56)$ & 149.1 & $(2.40)$ & 149.5 & $(0.87)$ \\
\hline \multicolumn{11}{|c|}{ Mean diastolic blood pressure $(\mathrm{mm} \mathrm{Hg})$} \\
\hline Male & 74.0 & $(0.30)$ & 76.7 & $(0.36)$ & 78.2 & $(0.39)$ & 80.9 & $(0.34)$ & 76.7 & $(0.21)$ \\
\hline 20 to 39 & 72.3 & $(0.39)$ & 75.3 & $(0.50)$ & 76.5 & $(0.71)$ & 80.6 & $(0.51)$ & 74.8 & $(0.32)$ \\
\hline 40 to 59 & 77.8 & $(0.52)$ & 79.2 & $(0.83)$ & 80.8 & $(0.58)$ & 82.7 & $(0.58)$ & 80.0 & $(0.31)$ \\
\hline 60 to 79 & 74.7 & $(0.52)$ & 76.3 & $(0.63)$ & 77.4 & $(0.45)$ & 78.3 & $(0.83)$ & 76.5 & $(0.36)$ \\
\hline $80+$ & 72.6 & $(0.74)$ & 73.9 & (1.03) & 74.2 & $(1.31)$ & 72.5 & $(1.52)$ & 73.2 & $(0.54)$ \\
\hline Female & 69.7 & $(0.28)$ & 72.4 & $(0.35)$ & 74.4 & $(0.40)$ & 76.0 & $(0.26)$ & 71.9 & $(0.22)$ \\
\hline 20 to 39 & 67.5 & $(0.38)$ & 70.0 & $(0.55)$ & 72.3 & $(0.71)$ & 74.6 & $(0.43)$ & 69.1 & $(0.29)$ \\
\hline 40 to 59 & 72.0 & $(0.39)$ & 74.6 & $(0.83)$ & 76.7 & $(0.64)$ & 78.9 & $(0.47)$ & 75.1 & $(0.28)$ \\
\hline 60 to 79 & 72.4 & $(0.47)$ & 73.3 & $(0.70)$ & 74.2 & $(0.63)$ & 74.2 & $(0.47)$ & 73.4 & $(0.34)$ \\
\hline $80+$ & 70.4 & $(0.69)$ & 71.9 & $(1.11)$ & 72.5 & (1.04) & 70.1 & $(1.30)$ & 70.9 & $(0.49)$ \\
\hline
\end{tabular}

of the increase occurred from a BMI of $<25$ to a BMI of 25 to 27 (Table 5 and Figure 1).

In regression analyses controlling for race/ethnicity, education, and smoking, the odds ratios for high blood cholesterol were higher at BMIs of $>25$ compared with BMIs of $<25$ (Figure 3). Hypercholesterolemia was not related to education or smoking in either sex (Table 6).

\section{HDL-C}

Mean levels of HDL-C were $\sim 10 \mathrm{mg} / \mathrm{dL}$ higher in women than in men and they decreased with increasing BMI in both sexes (Table 4). The mean HDL-C level for men with BMI $<25$ was $50 \mathrm{mg} / \mathrm{dL}$ and it declined to 40 $\mathrm{mg} / \mathrm{dL}$ at a BMI $\geq 30$. Among women, the age-adjusted mean HDL-C level decreased from $59 \mathrm{mg} / \mathrm{dL}$ for women with a BMI of $<25$ to $49 \mathrm{mg} / \mathrm{dL}$ for women with a BMI of $\geq 30$ (Table 4). Age-adjusted mean HDL-C levels were generally higher in black men and women than in white or
Mexican American men or women in all BMI groups (data not shown). The decline with increasing BMI was present among men and women in all race/ethnic groups and age groups.

Among men, the age-adjusted prevalence of low levels of HDL-C $(<35 \mathrm{mg} / \mathrm{dL})$ increased with increasing levels of BMI from $9 \%$ to $31 \%$ (Table 5). Black men had the lowest prevalence of low HDL at all levels of BMI (Figure 2). However, the pattern of increasing prevalence of low HDL with increasing BMI was generally similar among the three race/ethnic groups and among men in all age groups, including those 80 and older.

Among women, the age-adjusted prevalence of low HDL-C $(<45 \mathrm{mg} / \mathrm{dL})$ showed a pattern similar to that in men, increasing from $17 \%$ at a BMI of $<25$ to $41 \%$ at a BMI of $\geq 30$. The prevalence of low HDL-C was lowest among black women; it tended to be higher in Mexican American than white women at every level of BMI. 
Table 3. Prevalence of high blood pressure by BMI*

\begin{tabular}{|c|c|c|c|c|c|c|c|c|c|c|}
\hline & \multicolumn{2}{|c|}{ BMI $<25$} & \multicolumn{2}{|c|}{$25 \leq \mathrm{BMI}<27$} & \multicolumn{2}{|c|}{$27 \leq \mathrm{BMI}<30$} & \multicolumn{2}{|c|}{$30 \leq \mathrm{BMI}$} & \multicolumn{2}{|c|}{ Total $\dagger$} \\
\hline & $\%$ & (SE) & $\%$ & (SE) & $\%$ & (SE) & $\%$ & (SE) & $\%$ & (SE) \\
\hline Male & 14.9 & $(0.89)$ & 22.1 & $(1.79)$ & 27.0 & $(1.67)$ & 41.9 & $(2.18)$ & 24.0 & (1.04) \\
\hline 20 to 39 & 3.5 & $(0.63)$ & 7.4 & $(1.78)$ & 10.4 & $(2.27)$ & 24.6 & $(3.27)$ & 8.5 & $(0.86)$ \\
\hline 40 to 59 & 16.3 & $(1.76)$ & 23.3 & (3.46) & 30.2 & $(2.70)$ & 46.2 & $(4.06)$ & 28.6 & (1.56) \\
\hline 60 to 79 & 50.2 & $(2.41)$ & 51.6 & $(3.80)$ & 47.6 & $(3.37)$ & 61.5 & $(4.20)$ & 52.3 & (1.59) \\
\hline $80+$ & 59.3 & $(2.53)$ & 65.7 & $(3.65)$ & 62.6 & $(4.27)$ & 62.9 & $(7.16)$ & 61.8 & $(2.35)$ \\
\hline Female & 15.2 & $(0.95)$ & 27.7 & (1.47) & 32.7 & (2.04) & 37.8 & $(1.40)$ & 24.0 & $(0.86)$ \\
\hline 20 to 39 & 1.6 & $(0.40)$ & 2.0 & $(1.22)$ & 3.4 & $(0.65)$ & 11.2 & $(1.52)$ & 3.5 & $(0.45)$ \\
\hline 40 to 59 & 10.2 & $(1.22)$ & 20.0 & $(2.69)$ & 26.6 & $(2.86)$ & 39.4 & $(2.79)$ & 22.6 & $(1.32)$ \\
\hline 60 to 79 & 51.5 & $(2.36)$ & 60.4 & $(3.69)$ & 60.5 & $(3.91)$ & 72.4 & $(1.73)$ & 60.3 & (1.55) \\
\hline $80+$ & 75.2 & $(2.85)$ & 84.6 & $(3.81)$ & 85.3 & $(2.29)$ & 72.7 & $(5.61)$ & 78.2 & (1.63) \\
\hline
\end{tabular}

* Age 20 and older, excluding pregnant women. High blood pressure defined as average over three to six systolic blood pressure measures of $\geq 140 \mathrm{~mm} \mathrm{Hg}$, average over three to six diastolic blood pressure measures of $\geq 90 \mathrm{~mm} \mathrm{Hg}$, or currently taking antihypertensive medication.

$\uparrow$ Includes persons with missing BMI data.

However, the overall pattern of increasing prevalence of low HDL-C with increasing BMI was present among women in all race/ethnic groups and most age groups (Figures 1 and 2).

There was no consistent stepwise pattern of increasing prevalence of low HDL with increasing age in men or women. Nevertheless, the increase in the prevalence of low levels of HDL-C with increasing BMI was greater in younger men and women, where it was about twice as high in the overweight and three times as high in the obese groups as in the leanest groups (Table 5 and Figure 1). In regression analyses, low HDL-C was related positively to BMI, white vs. black race, and cigarette smoking; it was related inversely to years of education in women but not in men. Odds ratios for low HDL increased with increasing categories of BMI when race/ethnicity, smoking habits, and years of education were controlled (Figure 3 and Table 6). In age group-specific analyses, odds ratios were highest in the two youngest groups of men and the youngest group of women (Figure 3).

\section{Dyslipidemia}

When dyslipidemia was defined as a ratio of total cholesterol to HDL-C of $\geq 4.5$, the prevalence of this condition increased with increasing BMI level in both sexes and all race/ethnic groups. Prevalence rates were lower at ages 20 to 39 and increased with age in women but were lower in the oldest men compared with those aged 40 to 79 years.
Prevalence rates were lower in black men and women compared with other men and women (data not shown).

\section{Hypertension and Dyslipidemia}

The percentages of men and women with both high blood pressure and a lipid abnormality are shown in Figure 1, and the adjusted odds ratios are shown in Table 6 and Figures 2 and 3. The patterns of the combined prevalence of the two risk factors with increasing BMI and age are generally as expected from the patterns present for each risk factor separately; the association of BMI with both conditions together was strong in all analyses. Adjusted odds ratios increased across categories of BMI. Odds ratios for both abnormalities were generally lower in Mexican Americans than in whites or blacks, among women in smokers than nonsmokers, and in women with more education.

\section{Multivariate Odds Ratios}

Relationships between BMI and risk factors vary with sex, age, and race/ethnic group as shown in Tables 2 through 5 and Figures 1 through 3. The results of including interaction terms for BMI and age and for BMI and race/ ethnicity in multivariate models are shown in Table 6. The effect of BMI on high blood pressure is different for whites, blacks, and Mexican Americans as suggested by inspection of Figure 2 and confirmed by the analysis in Table 6. For example, the odds ratios for high blood pressure show that the chances of having high blood pressure with a BMI of 25 to 27 compared with a BMI of $<25$ is 2.4 times greater at ages 20 to 39 for white men $(2.4 \times 1.0 \times 1.0)$ and Mexican 

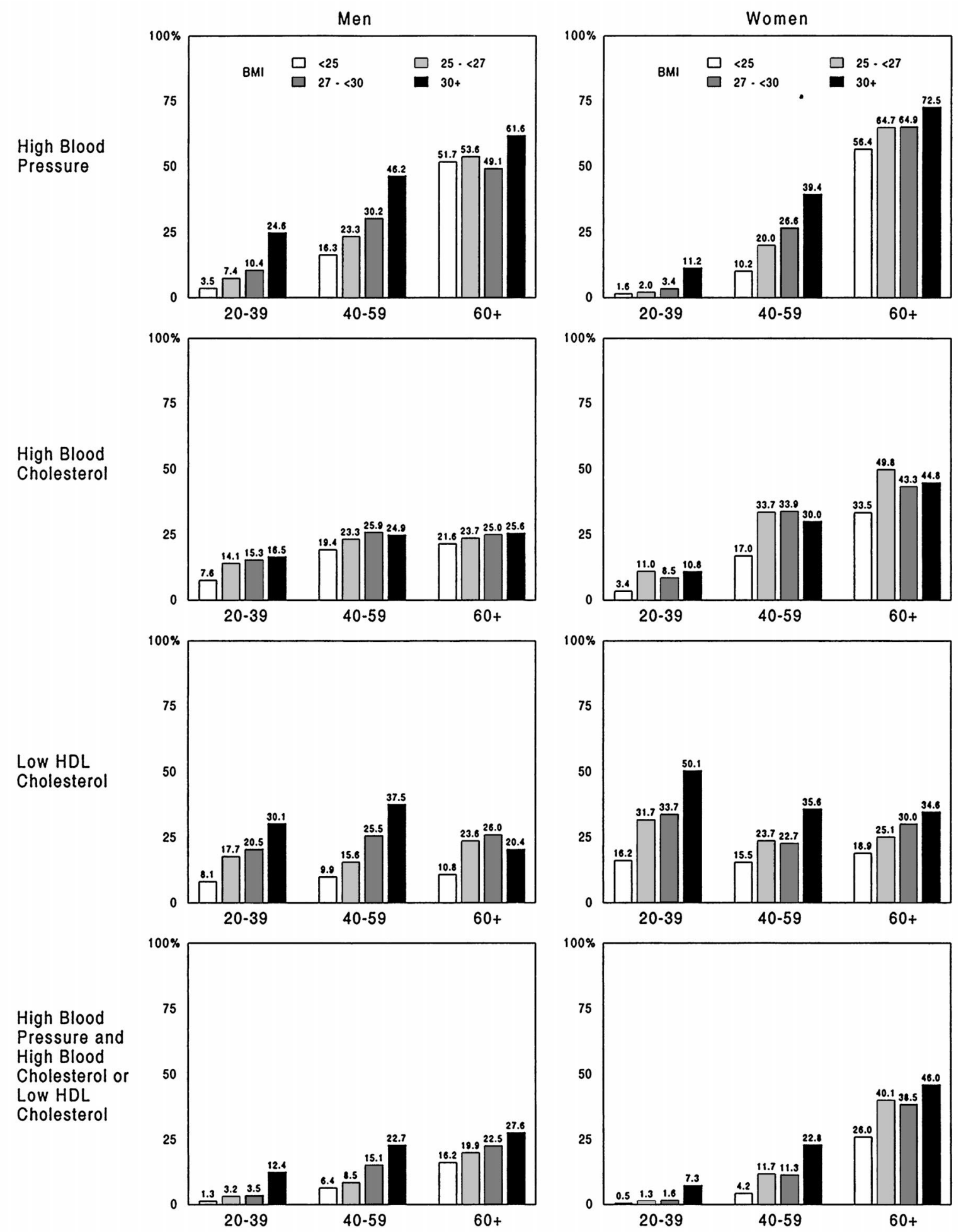

Figure 1. Prevalence of risk factors by sex, age, and BMI.

American men $(2.4 \times 0.7 \times 1.4)$ and 4.0 times greater for black men $(2.4 \times 2.1 \times 0.8)$. Similar calculations incorporating main effects and $\mathrm{BMI}-$ age interaction terms estimate odds ratios for high blood pressure at a BMI of 25 to 27 compared with a BMI of $<25$ to be 2.4 at ages 20 to $39,7.5$ at ages 40 to 59 , and 30.8 at ages 60 and older. For high blood cholesterol, odds ratios for BMIs of $\geq 25$ compared with BMIs of $<25$ are 2.2 for white men, 2.8 for black men, 

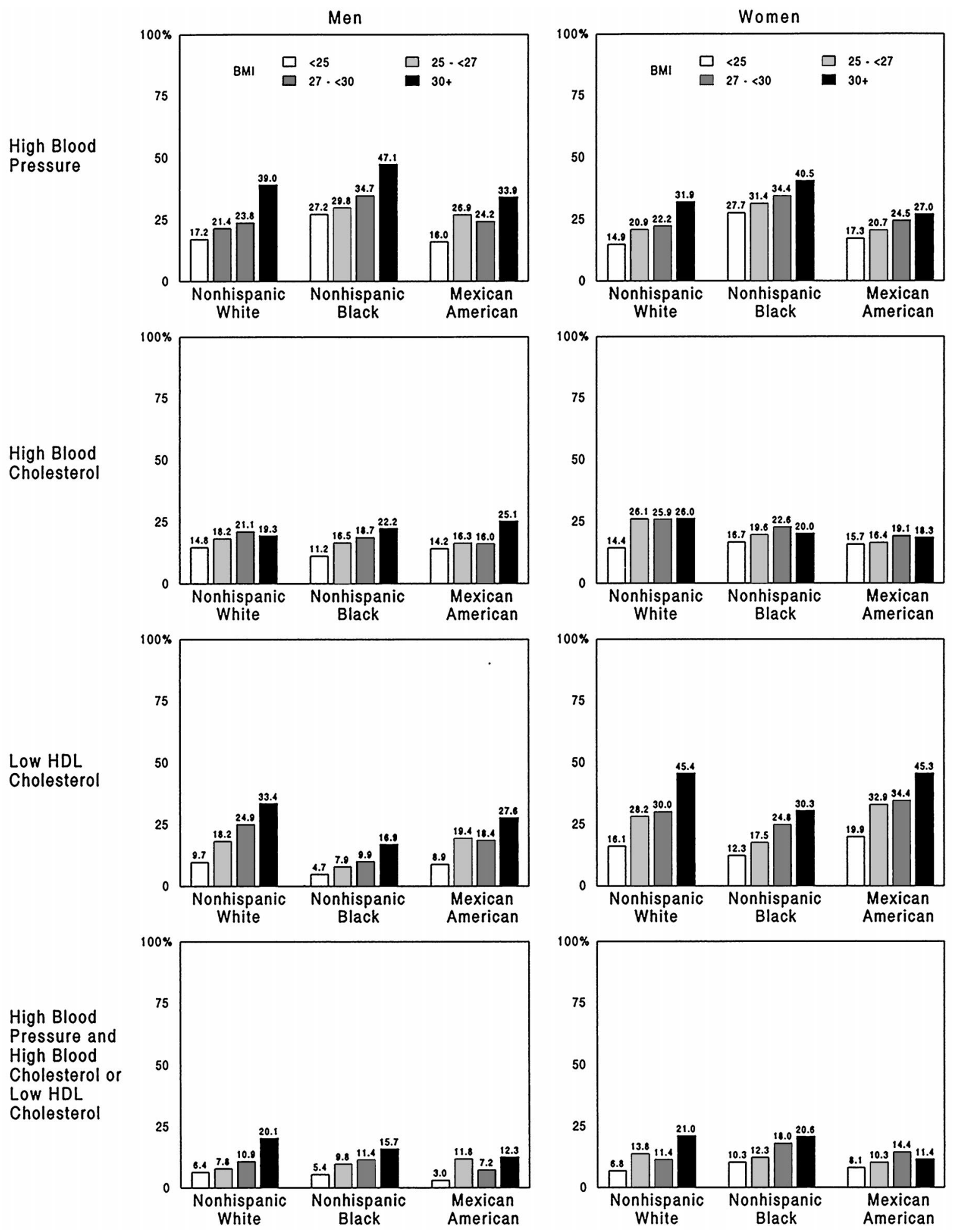

Figure 2. Age-adjusted prevalence of risk factors by sex, race/ethnicity, and BMI.

and 2.3 for Mexican American men. Comparable calculations for high blood cholesterol yield odds ratios of 2.2 at ages 20 to $39,1.3$ at ages 40 to 59, and 1.4 at ages 60 and older.
Based on the comprehensive multivariate analyses shown in Table 6, the effect of BMI was significant in all models. For men, the direct effects of age and the interaction between BMI and age were significant for high blood pressure 


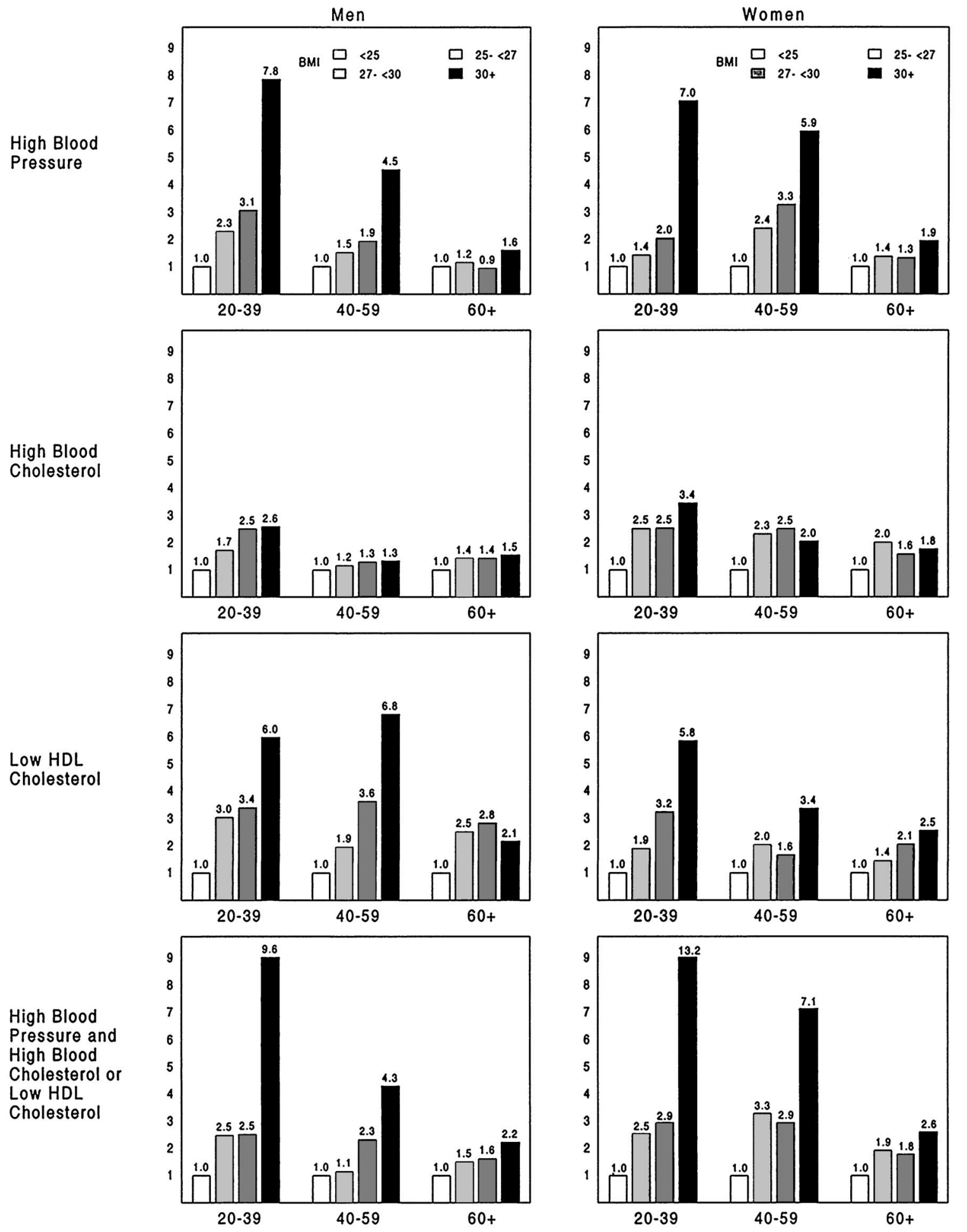

Figure 3. Odds ratio for risk factors by sex, age, and BMI.

and low HDL-C. For women, the direct effects of age and race and the interaction between $\mathrm{BMI}$ and age were significant for all risk factors except high blood cholesterol. In addition, the interaction between BMI and race/ethnicity was significant in women for all risk factors except low HDL cholesterol. In the multivariate models, the $r^{2}$ coefficients ranged from a high of 0.32 for high blood pressure among women to a low of 0.03 for high blood cholesterol 
Table 4. Mean total and HDL by BMI*

\begin{tabular}{|c|c|c|c|c|c|c|c|c|c|c|}
\hline & \multicolumn{2}{|c|}{ BMI $<25$} & \multicolumn{2}{|c|}{$25 \leq \mathrm{BMI}<27$} & \multicolumn{2}{|c|}{$27 \leq \mathrm{BMI}<30$} & \multicolumn{2}{|c|}{$30 \leq \mathrm{BMI}$} & \multicolumn{2}{|c|}{ Total $\dagger$} \\
\hline & $\%$ & (SE) & $\%$ & (SE) & $\%$ & (SE) & $\%$ & (SE) & $\%$ & (SE) \\
\hline \multicolumn{11}{|c|}{ Mean total cholesterol $(\mathrm{mg} / \mathrm{dL})$} \\
\hline Male & 192.7 & $(1.30)$ & 205.9 & $(1.71)$ & 208.5 & $(1.80)$ & 211.1 & $(1.64)$ & 202.1 & $(0.93)$ \\
\hline 20 to 39 & 181.6 & $(1.81)$ & 197.2 & $(2.69)$ & 196.8 & $(2.74)$ & 205.0 & $(2.80)$ & 190.7 & $(1.25)$ \\
\hline 40 to 59 & 206.6 & $(2.13)$ & 214.6 & $(2.40)$ & 216.4 & $(3.28)$ & 216.0 & $(2.69)$ & 212.9 & $(1.28)$ \\
\hline 60 to 79 & 211.6 & $(2.02)$ & 212.9 & $(2.38)$ & 217.3 & $(2.71)$ & 212.2 & $(2.86)$ & 213.5 & $(1.36)$ \\
\hline $80+$ & 200.1 & $(3.10)$ & 204.1 & $(3.40)$ & 197.2 & $(3.46)$ & 204.2 & $(6.70)$ & 200.8 & $(2.04)$ \\
\hline Female & 194.9 & (1.19) & 215.1 & $(2.01)$ & 217.2 & $(2.04)$ & 217.1 & $(1.45)$ & 206.1 & $(0.93)$ \\
\hline 20 to 39 & 177.3 & $(1.18)$ & 189.8 & (3.24) & 193.2 & $(2.90)$ & 196.8 & $(1.78)$ & 186.0 & (1.07) \\
\hline 40 to 59 & 204.5 & $(1.49)$ & 220.6 & $(3.43)$ & 221.8 & $(2.98)$ & 220.4 & $(2.67)$ & 213.7 & $(1.25)$ \\
\hline 60 to 79 & 226.4 & $(2.47)$ & 239.8 & $(3.14)$ & 235.0 & $(3.19)$ & 240.5 & $(2.24)$ & 234.0 & $(1.43)$ \\
\hline $80+$ & 224.5 & $(2.51)$ & 235.0 & $(4.03)$ & 223.6 & $(5.72)$ & 235.5 & $(4.83)$ & 227.9 & $(2.40)$ \\
\hline \multicolumn{11}{|c|}{ Mean HDL-C (mg/dL) } \\
\hline Male & 50.1 & $(0.46)$ & 45.1 & $(0.65)$ & 43.2 & $(0.53)$ & 40.1 & $(0.63)$ & 45.7 & $(0.37)$ \\
\hline 20 to 39 & 49.9 & $(0.60)$ & 44.2 & $(1.11)$ & 43.5 & $(0.92)$ & 40.1 & $(1.33)$ & 46.2 & $(0.48)$ \\
\hline 40 to 59 & 50.3 & $(1.00)$ & 46.7 & $(1.00)$ & 42.7 & $(0.84)$ & 38.5 & $(0.72)$ & 44.9 & $(0.55)$ \\
\hline 60 to 79 & 50.3 & $(0.74)$ & 44.7 & $(1.27)$ & 43.3 & $(0.87)$ & 43.0 & $(0.78)$ & 45.7 & $(0.51)$ \\
\hline $80+$ & 51.0 & $(0.84)$ & 44.8 & $(1.15)$ & 44.5 & $(1.50)$ & 40.2 & (1.70) & 47.4 & $(0.72)$ \\
\hline Female & 59.2 & $(0.55)$ & 53.5 & $(0.69)$ & 52.7 & $(0.53)$ & 48.9 & $(0.39)$ & 55.3 & $(0.41)$ \\
\hline 20 to 39 & 58.3 & $(0.63)$ & 50.6 & $(0.88)$ & 51.0 & $(1.05)$ & 46.4 & $(0.66)$ & 54.8 & $(0.52)$ \\
\hline 40 to 59 & 60.5 & (1.01) & 55.3 & (1.19) & 53.3 & $(0.86)$ & 49.9 & $(0.63)$ & 55.6 & $(0.67)$ \\
\hline 60 to 79 & 59.9 & $(0.91)$ & 55.4 & (1.17) & 54.2 & (1.14) & 51.2 & $(0.82)$ & 55.7 & $(0.53)$ \\
\hline $80+$ & 60.2 & $(1.17)$ & 53.9 & $(1.46)$ & 49.6 & $(1.46)$ & 51.0 & (1.69) & 55.7 & $(0.73)$ \\
\hline
\end{tabular}

among men. On average, the models accounted for only $10 \%$ of the variance of each risk factor among men and only $18 \%$ among women.

\section{Discussion}

These data show in greater detail the previously described positive relationships of BMI to systolic and diastolic blood pressures, and total cholesterol levels, as well as the negative relationship of BMI to HDL-C levels. In general, the prevalence of hypertension, high blood cholesterol, low HDL-C, and high total cholesterol to HDL-C ratio increase with increasing BMI, as does the combined prevalence of both hypertension and dyslipidemia. These relationships are found among men and women in all race/ethnic groups and in most age groups. Relative risks assessed by odds ratios are greater at younger ages, but prevalences of overweight, obesity, hypertension, and lipid abnormalities are higher at older ages. Odds ratios also vary among race/ethnic groups as indicated by the significant interaction terms. Although the impact of higher levels of BMI on prevalence of high blood pressure, abnormal lipids, and the two abnormalities together varies in terms of magnitude with sex, age, and race/ethnicity, the importance of increasing BMI as a determinant of these conditions is clear.

The inverse relationship between cigarette smoking and weight is well documented (44), and cigarette smokers have lower levels of HDL-C (45). Thus, failure to control for cigarette smoking will result in an underestimate of the association between BMI and low HDL-C.

Cardiovascular risk factors are also known to vary inversely with level of education and to cluster among those with the least amount of education. However, the relationship of BMI with high blood pressure and abnormal lipids persists when smoking habits and education as well as age and race/ethnicity are controlled in regression analyses. In other analyses based on NHANES III data, Must et al. (19) 
Table 5. Prevalence of high blood cholesterol and low HDL-C BMI*

\begin{tabular}{|c|c|c|c|c|c|c|c|c|c|c|}
\hline & \multicolumn{2}{|c|}{ BMI $<25$} & \multicolumn{2}{|c|}{$25 \leq$ BMI $<27$} & \multicolumn{2}{|c|}{$27 \leq \mathrm{BMI}<30$} & \multicolumn{2}{|c|}{$30 \leq \mathrm{BMI}$} & \multicolumn{2}{|c|}{ Total $\dagger$} \\
\hline & Pet & (SE) & Pct & (SE) & Pct & (SE) & Pet & (SE) & Pet & (SE) \\
\hline \multicolumn{11}{|c|}{ High blood cholesterol } \\
\hline Male & 13.0 & $(1.00)$ & 19.1 & $(1.38)$ & 21.6 & $(1.68)$ & 22.0 & $(1.67)$ & 17.7 & $(0.67)$ \\
\hline 20 to 39 & 7.6 & $(1.22)$ & 14.1 & $(2.48)$ & 15.3 & $(2.30)$ & 16.5 & $(2.80)$ & 11.5 & $(0.80)$ \\
\hline 40 to 59 & 19.4 & $(2.18)$ & 23.3 & $(3.36)$ & 25.9 & $(3.24)$ & 24.9 & $(2.49)$ & 23.1 & (1.45) \\
\hline 60 to 79 & 22.4 & $(2.16)$ & 24.6 & $(2.32)$ & 26.4 & $(2.92)$ & 25.9 & $(3.24)$ & 24.7 & $(1.25)$ \\
\hline $80+$ & 17.7 & $(2.77)$ & 18.6 & $(2.83)$ & 12.2 & $(3.14)$ & 18.8 & $(5.37)$ & 16.9 & $(2.00)$ \\
\hline Female & 13.4 & $(0.93)$ & 30.5 & $(2.39)$ & 29.6 & $(2.45)$ & 27.0 & $(1.38)$ & 21.3 & $(0.88)$ \\
\hline 20 to 39 & 3.4 & $(0.70)$ & 11.0 & $(2.30)$ & 8.5 & $(2.92)$ & 10.8 & $(1.75)$ & 7.6 & $(0.91)$ \\
\hline 40 to 59 & 17.0 & $(1.79)$ & 33.7 & $(4.09)$ & 33.9 & $(3.90)$ & 30.0 & $(2.31)$ & 25.4 & (1.30) \\
\hline 60 to 79 & 34.0 & $(2.55)$ & 50.3 & $(3.82)$ & 45.5 & $(3.26)$ & 45.2 & $(2.52)$ & 41.8 & (1.59) \\
\hline $80+$ & 31.3 & $(2.87)$ & 47.5 & $(4.00)$ & 33.1 & $(5.18)$ & 41.2 & $(6.37)$ & 36.0 & $(2.65)$ \\
\hline \multicolumn{11}{|l|}{ Low HDL-C } \\
\hline Male & 9.0 & $(0.88)$ & 18.2 & $(2.03)$ & 23.7 & $(1.84)$ & 31.1 & $(2.32)$ & 18.1 & (1.01) \\
\hline 20 to 39 & 8.1 & $(1.26)$ & 17.7 & $(3.89)$ & 20.5 & $(2.87)$ & 30.1 & $(4.60)$ & 15.3 & (1.61) \\
\hline 40 to 59 & 9.9 & (1.43) & 15.6 & $(2.53)$ & 25.5 & $(2.90)$ & 37.5 & $(2.88)$ & 21.6 & (1.30) \\
\hline 60 to 79 & 11.1 & $(1.60)$ & 24.5 & $(2.87)$ & 26.4 & $(2.84)$ & 19.6 & $(2.78)$ & 19.6 & (1.40) \\
\hline $80+$ & 9.0 & $(1.92)$ & 17.9 & $(3.17)$ & 22.3 & $(4.80)$ & 36.2 & $(8.72)$ & 15.9 & (2.08) \\
\hline Female & 16.6 & $(1.20)$ & 27.1 & (1.91) & 28.5 & (1.94) & 40.6 & $(1.61)$ & 25.1 & (1.01) \\
\hline 20 to 39 & 16.2 & $(1.62)$ & 31.7 & $(3.74)$ & 33.7 & (3.96) & 50.1 & $(2.53)$ & 25.6 & (1.60) \\
\hline 40 to 59 & 15.5 & $(2.18)$ & 23.7 & $(3.40)$ & 22.7 & $(2.87)$ & 35.6 & $(3.12)$ & 23.6 & (1.67) \\
\hline 60 to 79 & 18.5 & $(2.07)$ & 24.1 & (3.38) & 28.6 & $(2.53)$ & 34.6 & (2.18) & 25.8 & (1.25) \\
\hline $80+$ & 20.5 & $(2.47)$ & 29.6 & $(4.42)$ & 36.6 & $(5.91)$ & 34.4 & $(6.24)$ & 27.4 & (2.07) \\
\hline
\end{tabular}

\footnotetext{
* Age 20 and older, excluding pregnant women. High cholesterol defined as total cholesterol of $\geq 240 \mathrm{mg} / \mathrm{dL}$. Low HDL-C defined as HDL-C $<35 \mathrm{mg} / \mathrm{dL}$ for men and $<45 \mathrm{mg} / \mathrm{dL}$ for women.

$\dagger$ Includes persons with missing BMI data.
}

reported increased prevalence ratios by increasing severity of overweight and obesity for several health conditions, including high blood pressure. They also found higher prevalence ratios for high blood cholesterol among overweight and obese men and women than among normal weight persons. These investigators used different categories of BMI, different criteria to define high blood pressure and high blood cholesterol, and different analytic approaches than ours. Although their estimates of prevalence ratios and our odds ratios cannot be compared directly, results of the two studies are strongly concordant in identifying BMI as a risk factor for high blood pressure and high blood cholesterol.

Although cross-sectional studies do not provide information on the sequence of risk factor development, and causeand-effect relationships cannot be inferred, these findings are consistent with the cross-sectional, longitudinal, and clinical studies that show cardiovascular risk factors are more prevalent among overweight and obese people. Crosssectional studies in the United States and other countries have reported such relationships in both sexes, in a variety of ethnic groups, and in children and adults (11,13-19). Associations of adiposity at baseline and incidence of hypertension and dyslipidemia have been shown in large prospective cohort studies $(3,5,6,10,12,46)$. Clinical trials have shown the effect of weight loss on lowering blood pressures and improving lipid values (32,47-56). The science base for concluding that higher levels of body mass are causally related to higher levels of blood pressure and total cholesterol and lower levels of HDL-C is substantial and convincing.

National data show that whereas levels of blood pressure and cholesterol declined and HDL-C generally increased, mean levels of BMI and overweight and obesity increased over recent decades. The decline in mean systolic and diastolic blood pressures between 1976 and 1980 and 1988 
Body Mass Index, Blood Pressure, and Cholesterol, Brown et al.

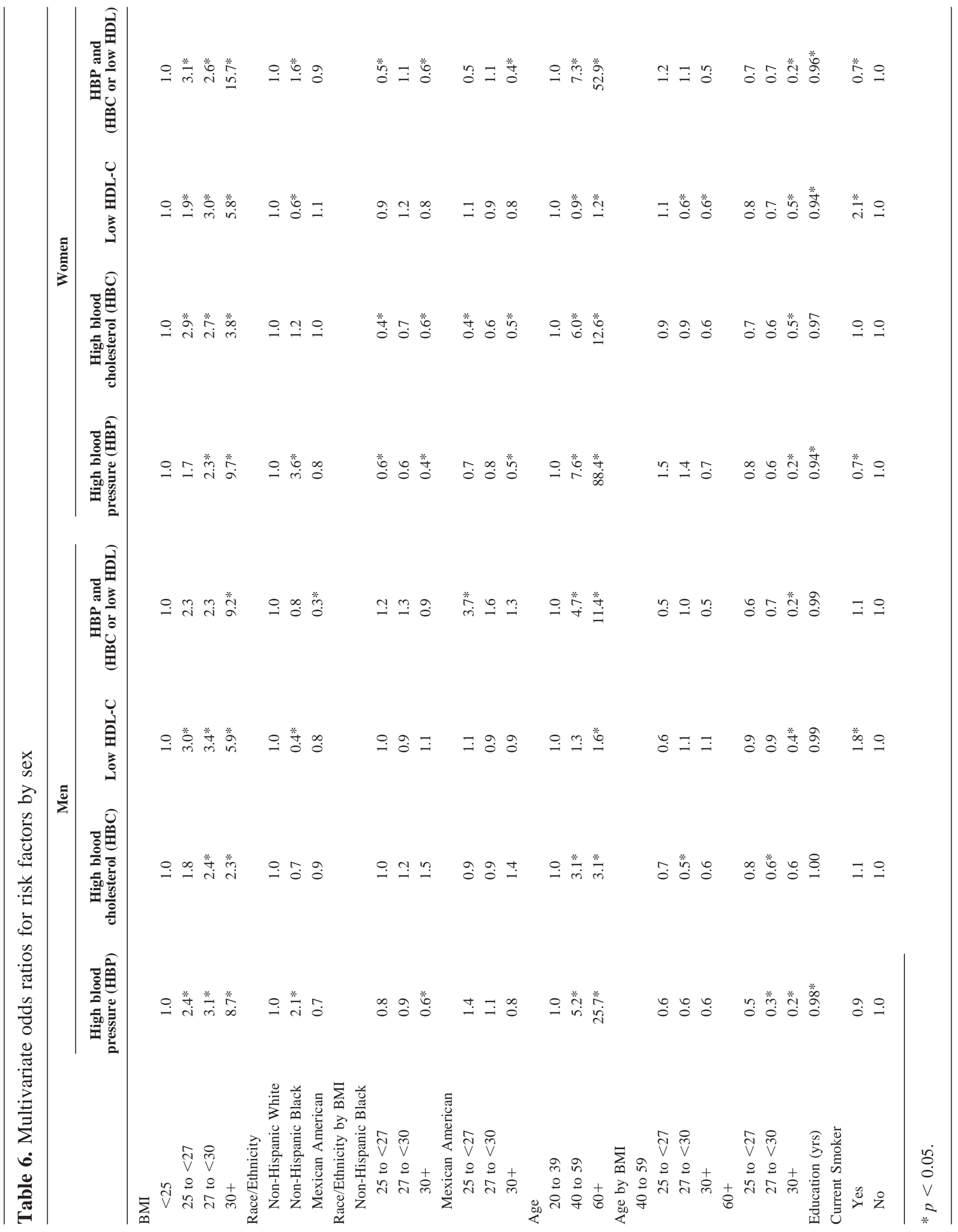


and 1991 occurred at all BMI levels (26). It has been suggested that the declining use of alcohol and dietary salt may have a role in the decline in the prevalence of high blood pressure, despite the increase in obesity (9). The beneficial trend in cholesterol is probably related to dietary changes (57), because only $\sim 2 \%$ of the population was using cholesterol-lowering medications during this time period (58). Previous analyses of the NHANES data have shown that the mean percentage of calories from total dietary fat and from saturated fat decreased from 1976 to 1980 and from 1988 to 1991; however, during that time, reported intake of total calories increased (56). Changes in calorie intake may reflect increased consumption or improved changes in the dietary protocol to obtain more complete intake information (59). Increased levels of physical inactivity $(60,61)$ as well as caloric intakes that are too high in relation to physical activity levels are probable explanations for the rising prevalence of overweight (32).

Smoking cessation has been shown to be related to weight gain. The prevalence of cigarette smoking has declined dramatically over the past 30 years, and a large proportion of the population has quit smoking (23). Reviews of the relationship between weight gain and smoking cessation have estimated that quitting smoking results in an average weight gain of between 4.5 and 7.5 pounds (50). From the NHANES III data, estimates of weight gain due to smoking cessation were 10 to 11 pounds. But smoking cessation accounted for only a small part of the recent increase in the prevalence of overweight; approximately one-quarter of the increase among men and approximately one-sixth of the increase among women could be attributed to smoking cessation $(62,63)$.

Limitations of this report include the fact that although BMI is highly correlated with body fatness (0.7 to 0.8) (64), it measures lean body mass as well as fat mass. It has been suggested that central, particularly visceral, fat is a more important contributor to cardiovascular risk than total body fat. Measures of regional adiposity such as waist circumference, waist-to-hip ratio, and subscapular to triceps skinfold thickness correlate highly with other measures of overweight such as BMI and may be even more strongly correlated with lipoprotein cholesterol fractions (64). However, the BMI-risk factor relationships have been shown to be independent of the measures used to characterize body weight or fat distribution. Some variability in the association of BMI and risk factors by sex, race/ethnic, and age groups is to be expected, given biological variability in blood pressure, total cholesterol, and HDL-C, and the importance of factors such as heredity, diet, and exercise, which are known to influence these variables.

The adverse relationship between BMI and cardiovascular risk factors is likely to be understated in these analyses because information on diabetes was not considered. Recent reports implicating overweight as a potent factor in the etiology of type 2 diabetes include an analysis of NHANES III data in which prevalence ratios for diabetes increased steeply with increasing levels of BMI; they were 2 to 18 times higher in obese than normal weight men and women, depending on the severity of obesity (19). A study of middle-aged women found that a BMI of 23 to 25 was associated with a fourfold increase in risk for diabetes mellitus compared with a BMI $<22$. These reports suggest that optimal weight for height may be lower than a BMI of $25(46,65)$, but being underweight is also associated with excess morbidity and mortality $(19,20,32)$.

\section{Conclusion}

The high prevalence of overweight is a major public health problem in the United States. Thirty-nine million Americans are estimated to have a BMI of $\geq 30$ and an additional 57 million to have a BMI of 25 to 29.9. This study quantifies for a representative national sample of the adult population the distribution of BMI, the relationship between BMI and blood pressure and lipid levels, and the excess prevalence of hypertension and dyslipidemia, separately and in combination among persons with a BMI of $\geq 25$. These findings indicate that levels of cardiovascular risk factors are substantially lower at a BMI of $<25$ than at higher BMI levels and suggest that levels of BMI that are used to define optimal weight, overweight, and obesity should take into account the strong and consistent relationships between BMI and cardiovascular risk factors and other health-related characteristics. Applying these prevalence estimates to the population yields estimates that 28 million Americans are obese (BMI of $>30$ ) and have high blood pressure, dyslipidemia, or both. Among those who are overweight (BMI of 25 to 29.9), 37 million have hypertension, dyslipidemia, or both conditions. Relative risks (indicated by odds ratios) and absolute risks (indicated by prevalence rates) are both important in determining clinical practice and public health approaches to case finding, treatment, and prevention of overweight, obesity, high blood pressure, lipid abnormalities, and related conditions.

\section{Acknowledgments}

The National Heart, Lung, and Blood Institute provided support for this analysis. We acknowledge the technical advice of Clifford Johnson of the National Center for Health Statistics and Heather Seid from CODA. M.H. is retired from the National Heart, Lung, and Blood Institute.

\section{References}

1. Hubert HB, Feinleib M, McNamara PM, Castelli WP. Obesity as an independent risk factor of cardiovascular disease: a 26-year follow-up of participants in the Framingham Heart Study. Circulation. 1983;67:968-77.

2. Van Itallie T. Health implications of overweight and obesity in the United States. Ann Intern Med. 1985;103:983-8. 
3. Higgins M, Kannel W, Garrison R, Pinsky J, Stokes J. Hazards of obesity: the Framingham experience. Acta Med Scand Suppl. 1988;723:23-6.

4. Pi-Sunyer FX. Health implications of obesity. Am J Clin Nutr. 1991;53:1595S-1603S.

5. Manson JE, Willett WC, Stampfer MJ, et al. Body weight and mortality among women. $N$ Engl J Med. 1995;333: 677-85.

6. Manson JE, Colditz GA, Stampfer MJ, et al. A prospective study of obesity and risk of coronary heart disease in women. N Engl J Med. 1990;322:882-9.

7. Stamler J. Epidemiologic findings on body mass and blood pressure in adults. Ann Epidemiol. 1991;1:347-62.

8. MacMahon S, Cutler J, Brittian E, Higgins M. Obesity and hypertension: epidemiological and clinical issues. Eur Heart J. 1987;8:57-70.

9. Roccella EJ, Burt V, Horan MJ, Cutler J. Changes in hypertension awareness, treatment, and control rates: 20-year trend data. Ann Epidemiol. 1993;3:547-9.

10. Witteman JC, Willett WC, Stampfer MJ, et al. A prospective study of nutritional factors and hypertension among US women. Circulation. 1989;80:1320-7.

11. Keys A, ed. Coronary heart disease in seven countries. Circulation. 1970;41(Suppl 1):1-211.

12. Gillum RF, Taylor HL, Brozek J, Polansky P, Blackburn H. Indices of obesity and blood pressure in young men followed 32 years. J Chronic Dis. 1982;35:211-9.

13. Denke MA, Sempos CT, Grundy SM. Excess body weight: an under-recognized contributor to dyslipidemia in white American women. Arch Intern Med. 1994;154:401-10.

14. Denke MA, Sempos CT, Grundy SM. Excess body weight: an underrecognized contributor to high blood cholesterol levels in white American men. Arch Intern Med. 1993;153:1093103.

15. Montoye HJ, Epstein FH, Kjelsberg MO. Relationship between serum cholesterol and body fatness: an epidemiological study. Am J Clin Nutr. 1966;18:397-406.

16. Jacobs DR, Burke GL, Liu K, et. al. Relationships of lowdensity lipoprotein cholesterol with age and other factors: a cross-sectional analysis of the CARDIA Study. Am Clin Res. 1988;70:32-8.

17. Morrison JA, Payne G, Barton BA, Khoury PR, Crawford P. Mother-daughter correlations of obesity and cardiovascular disease risk factors in black and white households: the NHLBI Growth and Health Study. Am J Public Health. 1994;84:1761-7.

18. Birmingham B, Dyer AR, Shekelle RB, Stamler J. Subscapular and triceps skinfold thickness, body mass index, and cardiovascular risk factors in a cohort of middle-aged employed men. J Clin Epidemiol. 1993;46:289-302.

19. Must A, Spadano J, Coakley EH, Field AE, Colditz G, Dietz WH. The disease burden associated with overweight and obesity. JAMA. 1999;282:1523-9.

20. Calle EE, Thun J, Petrelli JM, Rodriguez G, Heath CW Jr. Body mass index and mortality in a prospective cohort of U.S. adults. N Engl J Med. 1999;341:1097-105.

21. Kuczmarski RJ, Flegal KM, Campbell SM, Johnson CL. Increasing prevalence of overweight among US adults: The
National Health and Nutrition Examination Surveys, 1960 to 1991. JAMA. 1994;272:205-11.

22. Mokdad AH, Serdula MK, Dietz WH, Bowman BA, Marks JS, Koplan JP. The spread of the obesity epidemic in the United States, 1991-1998. JAMA. 1999;282:1519-22.

23. National Center for Health Statistics. Health. United States. Hyattsville, MD: National Center for Health Statistics; 1998.

24. Allison DB, Fontaine KR, Manson JE, Stevens J, VanItallie TB. Annual deaths attributable to obesity in the United States. JAMA. 1999;282:1530-8.

25. Burt VL, Welton P, Roccella EJ, et al. Prevalence of hypertension in the US adult population. Results from the Third National Health and Nutrition Examination Survey, 19881991. Hypertension. 1995;25:305-13.

26. Burt VL, Colter JA, Higgins M, et al. Trends in the prevalence, awareness, treatment, and control of hypertension in the adult US population. Data from the health examination surveys, 1960 to 1991. Hypertension. 1995;26:60-9.

27. Johnson CL, Rifkind BM, Sempos CT, et al. Declining serum total cholesterol levels among US adults. The National Health and Nutrition Examination Surveys. JAMA. 1993;269: 3002-8.

28. Sempos CT, Cleeman JI, Carroll MD, et al. Prevalence of high blood cholesterol among adults. An update based on guidelines from the second report of the National Cholesterol Education Program Adult Treatment Panel. JAMA. 1993;269: 3009-14.

29. Troiano RP, Flegal KM, Kuczmarski RJ, et al. Overweight prevalence and trends for children and adolescents. The National Health and Nutrition Examination Surveys. 1963 to 1991. Arch Pediatr Adolesc Med. 1995;149:1085-91.

30. Dittus KL, Beerman KA, Schneckenburger CA. A comparison of three anthropometric measurement classifications for assessing body weight. Top Clin Nutr. 1995;10:58-66.

31. Weigley ES. The body mass index in clinical practice. Top Clin Nutr. 1994;9:70-5.

32. National Institutes of Health. Clinical Guidelines on the Identification, Evaluation and Treatment of Overweight and Obesity in Adults: Evidence Report. Bethesda, MD: National Institutes of Health; 1998, Publication no. 98-4083.

33. Ezzati TM, Massey JT, Waksburg J, Chu A, Maurer KR. Sample design: Third National Health and Nutrition Examination Survey. Vital Health Stat 2. 1992;113:1-35.

34. National Center for Health Statistics. Plan and operation of the third National Health and Nutrition Examination Survey, 1988-1994. Series 1: programs and collection procedures. Vital Health Stat 1. 1994;32:1-407.

35. World Health Organization. Obesity: Preventing and Managing the Global Epidemic. Report of the WHO Consultation on Obesity. Geneva: World Health Organization; 1998.

36. National Research Council. Committee on Diet and Health. Implications for Reducing Chronic Disease Risk. Washington, DC: National Academy Press; 1989.

37. World Health Organization. Physical Status: The Use and Interpretation of Anthropometry. Report of a WHO Expert Committee. Geneva: World Health Organization, Technical Report Series; 1995;854:1-452. 
38. United States Department of Agriculture Food and Nutrition Information Center. Nutrition and Your Health: Dietary Guidelines for Americans. 3rd ed. Washington, DC: Government Printing Office; 1995.

39. Sichieri R, Everhart JE, Hubbard VS. Relative weight classifications in the assessment of underweight and overweight in the United States. Int J Obes. 1992;16:303-12.

40. National High Blood Pressure Education Program. The Sixth Report of the Joint National Committee on Prevention, Detection, Evaluation, and Treatment of High Blood Pressure. Bethesda, MD: National Institutes of Health; 1997, Publication no. 98-4080.

41. National Cholesterol Education Program. Second Report of the Expert Panel on Detection, Evaluation and Treatment of High Blood Cholesterol in Adults. (Adult Treatment Panel II). Circulation. 1994;89:1333-445.

42. National Center for Health Statistics. Analytic and reporting guidelines. In: NHANES III. Reference Manuals and Reports. [CD-ROM]. Hyattsville, MD: National Center for Health Statistics; 1996.

43. Shah BV, Barnwell BG, Hunt PN, Nileen P, LaVange LM. SUDAAN User's Manual, Release 5.50. Research Triangle Park, NC: Research Triangle Institute; 1991.

44. Albanes D, Jones Y, Micozzi MS, Mattson ME. Associations between smoking and body weight in the US population: analysis of NHANES II. Am J Public Health. 1987;77: 439-44.

45. Garrison RJ, Kannel WB, Feinleib M, Castelli WP, McNamara PM, Padgett SJ. Cigarette smoking and HDL cholesterol: the Framingham offspring study. Atherosclerosis. 1978;30:17-25.

46. Willett WC, Manson JE, Stampfer MJ, et al. Weight, weight change, and coronary heart disease in women: risk within the "normal" weight range. JAMA. 1995;273:461-5.

47. Cutler J. Randomized clinical trials of weight reduction in nonhypertensive persons. Ann Epidemiol. 1991;1:363-70.

48. Trials of Hypertension Prevention Collaborative Group. The effects of nonpharmacologic interventions on blood pressure of persons with high normal levels. Results of the Trials of Hypertension Prevention, Phase I. JAMA. 1992;267: 1213-20.

49. Davis BR, Blauxfox MD, Oberman A, et al. Reduction in long-term antihypertensive medication requirements. Effects of weight reduction by dietary intervention in overweight persons with hypertension. Arch Intern Med. 1993;153: 1773-82.

50. Applegate WB, Miller ST, Zelam JT, et al. Nonpharmacologic intervention to reduce blood pressure in older patients with mild hypertension. Arch Intern Med. 1992;152:1162-6.

51. Grundy SM, Denke MA. Dietary influences on serum lipids and lipoproteins. J Lipid Res. 1990;31:1149-72.
52. Caggiula AW, Christakis G, Farrand M, et al. The multiple risk intervention trial (MRFIT). IV. Intervention on blood lipids. Prev Med. 1981;10:443-75.

53. Dattilo AM, Kris-Etherton PM. Effects of weight reduction on blood lipids and lipoproteins: a meta-analysis. Am J Clin Nutr. 1992;56:320-8.

54. Wood PD, Stefanick ML, Williams PT, Haskell WL. The effects on plasma lipoproteins of a prudent weight-reducing diet with or without exercise, in overweight men and women. N Engl J Med. 1991;325:461-6.

55. Wood PD, Stefanick ML, Dreon DM, et al. Changes in plasma lipids and lipoproteins in overweight men during weight loss through dieting as compared with exercise. $N$ Engl J Med. 1988;319:1173-9.

56. Centers for Disease Control and Prevention. Daily dietary fat and total food-energy intakes: Third National Health and Nutrition Examination Survey, Phase 1, 1988-91. MMWR Morb Mortal Wkly Rep. 1994;43:116-7.

57. Ernst ND, Sempos CT, Briefel RR, Clark MB. Consistency between US dietary fat intake and serum total cholesterol concentrations: the National Health and Nutrition Examination Surveys. Am J Clin Nutr. 1997;66(Suppl 4):965S-72S.

58. Schucker B, Wittes JT, Santanello NC, et al. Change in cholesterol awareness and action. Results from national and public surveys. Arch Intern Med. 1991;151:666-73.

59. Briefel RR, McDowell MA, Alaimo K, et al. Total energy intake of the US population: the third National Health and Nutrition Examination Survey, 1988-1991. Am J Clin Nutr. 1995:62(Suppl 4):1072S-80S.

60. Centers for Disease Control and Prevention. Prevalence of sedentary lifestyle: Behavioral Risk Factor Surveillance System, United States, 1991. MMWR Morb Mortal Wkly Rep. 1993;42:576-9.

61. Ernst ND, Obarzanek E, Clark MB, Briefel RR, Brown CD, Donato K. Cardiovascular health risks related to overweight. J Am Diet Assoc. 1997;97:S47-51.

62. Williamson DF, Madans J, Anda RF, Kleinman JC, Gavin GA, Byers T. Smoking cessation and severity of weight gain in a national cohort. N Engl J Med. 1991;324: $739-45$.

63. Flegal KM, Troiano R, Pamuck E, Kuczmarski R, Campbell S. The influence of smoking cessation on the prevalence of overweight in the United States. $N$ Engl J Med. 1995;333:1165-70.

64. Bjorntorp P. Visceral obesity: a "civilization syndrome." Obes Res. 1993;1:206-22.

65. Colditz GA, Willett WC, Rotnitzky A, Manson JE. Weight gain as a risk factor for clinical diabetes mellitus in women. Ann Intern Med. 1995;122:481-6. 